\title{
Median sacral artery injury during percutaneous mechanical disc decompression using Dekompressor ${ }^{\circledR}$
}

\author{
Young Uk Kim ${ }^{1}$, Eun Young Chae ${ }^{2}$, Ji Hoon Lee ${ }^{3}$, Chang Hee Lee ${ }^{4}$, and Young Ki Kim ${ }^{4}$ \\ Departments of ${ }^{1}$ Anesthesiology and Pain Medicine, ${ }^{2}$ Radiology, Research Institute of Radiology, Asan Medical Center, University \\ of Ulsan College of Medicine, Seoul, ${ }^{3}$ Deparment of Neurosurgery, Gil Medical Center, Gachon University, Incheon, ${ }^{4}$ Department of \\ Anesthesiology and Pain Medicine, Gangneung Asan Hospital, University of Ulsan College of Medicine, Gangneung, Korea
}

Disc decompression using the Dekompressor ${ }^{\circledR}$ (Stryker, Kalamazoo, MI, USA) is an effective procedure for treating patients with contained disc herniation [1-5]. Iatrogenic vascular injuries during lumbar disc decompression, although rare, are serious complications, that can be fatal without prompt diagnosis and management [5]. In this paper we present the case of a 23-yearold man with median sacral artery injury during lumbar disc decompression using the Dekompressor ${ }^{\circledR}$. After the procedure, blood pressure decreased, and dizziness, and abdominal pain occurred in the recovery room. Abdomino-pelvic computed to- mography (CT) without contrast medium showed a $7.5 \mathrm{~cm}$ sized hematoma in the left prevertebral space of the L5-S1 level. Leakage of contrast medium from the median sacral artery was noted by a contrast-enhanced CT scan (Fig. 1). Fortunately, the patient's vital signs were generally maintained by rapid transfusion. The next day, the patient underwent a repeat contrast-enhanced CT scan. There was no definite contrast extravasation, and the size of the retroperitoneal hematoma had decreased from 7.5 to $6 \mathrm{~cm}$. The patient was treated by conservative management and recovered uneventfully.
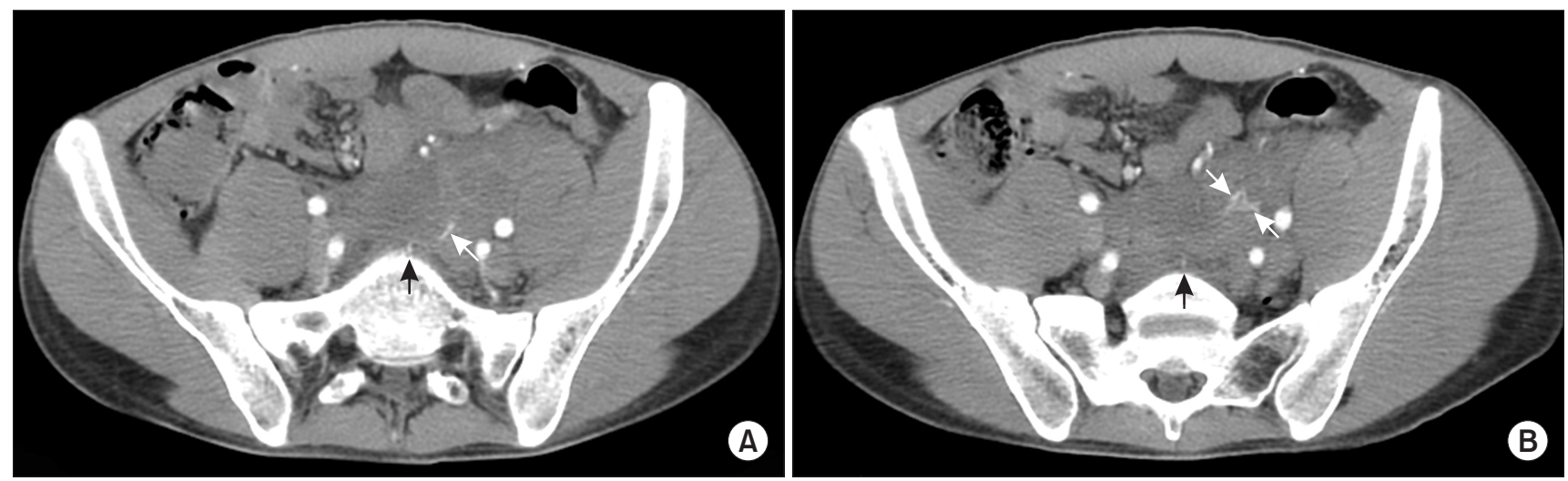

Fig. 1. Contrast-enhanced CT images (A and B) show focal areas of high attenuation (white arrows) from the median sacral artery (black arrows) within the hematoma, a finding that represents an active bleeding.

Corresponding author: Young Ki Kim, M.D., Department of Anesthesiology and Pain Medicine, University of Ulsan College of Medicine, Gangneung Asan Hospital, 38, Bangdong-gil, Sacheon-myeon, Gangneung 210-711, Korea Tel: 82-33-610-3114, Fax: 82-33-610-3409, E-mail: ykkim@gnah.co.kr

(c) This is an open-access article distributed under the terms of the Creative Commons Attribution Non-Commercial License (http:// creativecommons.org/licenses/by-nc/3.0/), which permits unrestricted non-commercial use, distribution, and reproduction in any medium, provided the original work is properly cited. 


\section{References}

1. Han SS, Sim SE, Kim YH, Lee EH, Joh JY, Kim JY, et al. Clinical outcomes of percutaneous lumbar discectomy using Dekompressor. Korean J Pain 2005; 18: 187-91.

2. Kim YH, Gu MS, Lee EH, Joh JY, Han SS, Lee CJ, et al. Percutaneous cervical discectomy using Dekompressor. Korean J Pain 2005; 18: $271-4$.

3. Cho OG, Kim C, Han KR, Lee HH, Cho HW. Percutaneous discectomy of herniated intervertebral disc with a Dekompressor. Korean J Pain 2005; 18: 192-7.

4. Lemcke J, Al-Zain F, Mutze S, Meier U. Minimally invasive spinal surgery using nucleoplasty and the Dekompressor tool: a comparison of two methods in a one year follow-up. Minim Invasive Neurosurg 2010; 53: 236-42.

5. Singh V, Benyamin RM, Datta S, Falco FJ, Helm S 2nd, Manchikanti L. Systematic review of percutaneous lumbar mechanical disc decompression utilizing Dekompressor. Pain Physician 2009; 12: 589-99. 